\title{
Systemic Lupus Erythematosus with Sensorineural Hearing Loss and Improvement after Plasmapheresis Using the Double Filtration Method
}

\author{
Sentaro Kobayashi, Noboru Fujishiro and Kazuko SugiYama*
}

\begin{abstract}
A 32-year-old female was diagnosed as having systemic lupus erythematosus based on her laboratory tests. In 1985 she began to complain of hearing difficulty. Her hearing ability deteriorated to the extent that her audiogram revealed a hearing loss of $90 \mathrm{db}$ to $110 \mathrm{db}$ in both ears in September 1989. She received two series of plasmapheresis treatments using the double filtration method. After two series of plasmapheresis treatments, her hearing improved dramatically. This improvement suggests that circulating immune complexes and anti-phospholipid antibodies might play a pathological role in the hearing impairment in SLE patient.
\end{abstract}

(Internal Medicine 31: 778-781, 1992)

Key words: anti-phospholipid antibodies, cerebral thrombosis, double filtration method, epilepsy, immune complexes, micro-circulation

\section{Case Report}

A-32-year-old female first consulted her physician because of palmar erythema in 1983 . She was diagnosed as having systemic lupus erythematosus (SLE) based on her serological analysis. Fever, hand edema, proteinuria, arthralgia and myalgia were also present. A butterflyrash and an increased blood sedimentation rate were also observed. She was treated with a low dosage of steroids for a short period.

She was referred to our hospital three months later. Her laboratory findings were positive for anti-DNA antibodies and anti-nuclear antibodies and a consistently low level of complements. Echocardiographic examination of her heart showed mild mitral regurgitation and a small verruca under the frontal leaf of the mitral valve. In 1988 she experienced convulsions, and her electroencephalogram showed the typical spike-andwave pattern observed in epilepsy. Her brain CT scan showed a small low density area near the left ventricle of the cerebrum.

She began to complain of hearing difficulties in 1985. In spite of intensive treatment, including steroids, her hearing deteriorated gradually to the extent that her audiogram revealed losses of $100 \mathrm{db}$ in both ears by September 1989. She received two series of plasmapher- esis treatments using the double filtration method at the end of 1989. Each series of plasmapheresis treatments lasted 4 consecutive days. After the second series of plasmapheresis, her hearing improved dramatically.

There was no history of any particular diseases in her family. Her physical findings at admission were a systolic murmur at the base of her heart and no palpable lymph nodes. The liver and spleen were not enlarged. She had a consistent low grade fever which was not controlled by steroids.

\section{Laboratory Tests}

Laboratory tests were performed prior to plasmapheresis treatment in November 1989 and the results were as follows: Urinalysis as negative for protein, glucose and bile. Her urinary sediments were normal. Hematological findings disclosed that her hemoglobin was $12.9 \mathrm{~g} / \mathrm{dl}$, the red cell count $398 \times 10^{4} / \mathrm{mm}^{3}$, the white cell count 6,200 and the platelet count was 225,000 . Prothrombin time was 15.4 seconds. Activated partial thromboplastin time was prolonged at 61.6 seconds. Lupus anti-coagulant tests were positive and anti-phospholipid antibodies such as anti-phosphatidyl serine antibody, anti-cardiolipin, anti-phosphatidyl inositol, phosphatidyl glycerol and phosphatidic acid were also positive. Anti-

From the Department of Internal Medicine and *Department of Otology, Meijo-Hospital, Nagoya

Received for publication December 18, 1990; Accepted for publication February 10, 1992

Reprint requests should be addressed to Dr. Sentaro Kobayashi, the Department of Internal Medicine, Meijo-Hospital, 1-3-1 Sannomaru, Naka-ku, Nagoya 460, Japan 
nuclear antibodies were positive $(\times 640)$. The anti-DNA antibody for double stranded DNA was $0.4 \mathrm{U} / \mathrm{ml}$, and the antibody for the anti-single stranded DNA was $5.7 \mathrm{U} / \mathrm{ml}$. Serum complement levels were consistently low; C3 $30.8 \mathrm{mg} / \mathrm{dl}, \mathrm{C} 47.3 \mathrm{mg} / \mathrm{dl}$, and CH50 $27.7 \mathrm{U} / \mathrm{ml}$. The immune complex level, measured by $\mathrm{Clq}$ binding assay (1), was $22.7 \mu \mathrm{g} / \mathrm{ml}$ (normal $\leqq 35.5$ ). Her serum total protein was $6.9 \mathrm{~g} / \mathrm{dl}$, serum albumin $4.4 \mathrm{~g} / \mathrm{dl}$, GOT 15 and GPT $4 \mathrm{KU} / \mathrm{ml}$, LDH $385 \mathrm{IU} / 1$, amylase $108 \mathrm{IU} / 1$, CPK $39 \mathrm{IU} / 1$. BUN was $11.1 \mathrm{mg} / \mathrm{dl}$, creatinine $1.58 \mathrm{mg} / \mathrm{dl}$, $\mathrm{Na} 139.4 \mathrm{mEq} / \mathrm{l}, \mathrm{K} 3.4, \mathrm{Cl} 95, \mathrm{Ca} 9.5 \mathrm{mg} / \mathrm{dl}, \mathrm{P} 5.2 \mathrm{mg} / \mathrm{dl}$ and total cholesterol $177 \mathrm{mg} / \mathrm{dl}$. Her cerebrospinal fluid showed total protein of $33 \mathrm{mg} / \mathrm{dl}$, with a relatively high content of $\mathrm{IgG}, 4.122 \mathrm{mg} / \mathrm{dl}$; normal $\operatorname{IgA}, 0.225 \mathrm{mg} / \mathrm{dl}$; and $\operatorname{IgM}, 0.06 \mathrm{mg} / \mathrm{dl}$.

The echocardiogram revealed mild mitral regurgitation and a small verruca under the frontal leaf of the mitral valve. The patient's electroencephalogram in 1988 showed the typical spike-and-wave pattern of epilepsy (Fig. 1). The audiogram showed sensorineural hearing loss of 90 to $110 \mathrm{db}$ in both ears (Fig. 2).

\section{Plasmapheresis}

Plasmapheresis was performed by the double filtration method (2) using KM8800 apparatus (Kurare). A polyvinyl-alcohol membrane was used for the first

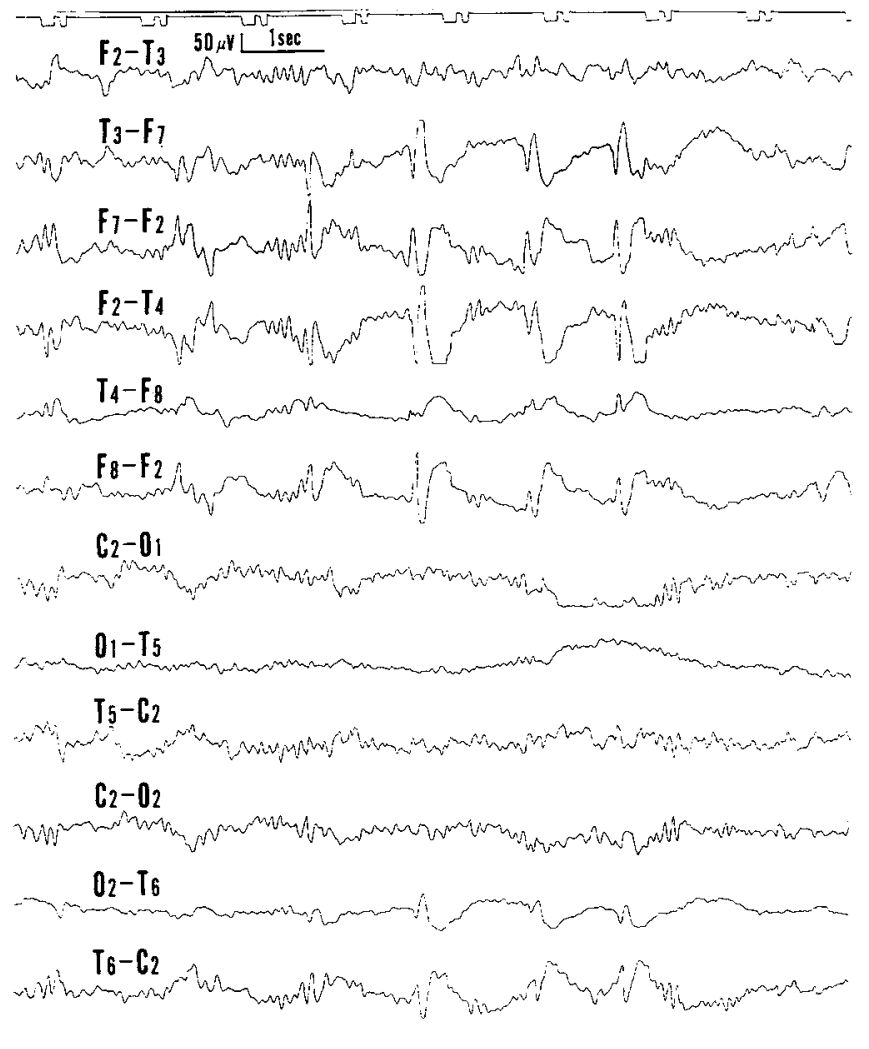

Fig. 1. The patient's electroencephalography in 1988 showing the typical "spike-and-wave" pattern observed in epilepsy patients. filter as the plasmaseparator, and an ethylene vinylalcohol membrane was used as the second filter to separate the macromolecules with a molecular weight of larger than $2 \times 10^{6}$. Simultaneously $700 \mathrm{ml}$ of serum was discarded and replaced by $700 \mathrm{ml}$ of fluid containing $4.4 \%$ albumin. This plasmapheresis treatment was performed for 4 consecutive days.

The patient's hearing at the onset of the disease was normal, but there was a gradual loss of 60 to $70 \mathrm{db}$ in the middle tones in 1986 and $110 \mathrm{db}$ loss was observed in September 1989 (Fig. 2). This hearing impairment necessitated the use of a hearing aid.

The first series of plasmapheresis treatments was performed at the end of 1989. Her hearing improved dramatically after the first series of plasmapheresis as recorded in her audiogram (Fig. 3). After the second series of plasmapheresis, her hearing loss improved to 40 to $60 \mathrm{db}$, the level similar to that observed in 1986. This improvement lasted for several weeks and the severe hearing loss observed in September 1989 never recurred.

Prior to the treatment, her serum immune complex level was $22.7 \mu \mathrm{l} / \mathrm{ml}$ and was reduced to less than $10 \mu \mathrm{l} / \mathrm{ml}$ after the first series of plasmapheresis. The titer levels of anti-nuclear antibody and the level of complements and anti-DNA antibodies did not change remarkably after plasmapheresis. The positive level of anti-phospholipid antibodies did became negative after two series of plasmapheresis (Fig. 4).

\section{Discussion}

Bowman et al (3) reported that hearing loss is observed in $8 \%$ of SLE patients. Hearing loss in these cases was not related to age, sex, disease activity, duration of symptoms of SLE, or to other organ-system involvement such as kidney and brain. They emphasized the importance of audiological screening tests in SLE patients. One case of SLE with hearing impairment reported by Caldarelli et al (4), showed no hearing improvement after treatment with prednisolone and cyclophosphamide. Another case of hearing loss, caused by an autoimmune mechanism affecting the inner ear, was reported to have responded favorably to steroids and immunosuppressive reagents (5).

Successful treatment of systemic vascular diseases by plasma exchange was first reported by Lookwood et al (6). Hamblin et al (7) showed that hearing loss of an SLE patient was improved temporarily by plasmapheresis treatment. The present study also disclosed that plasmapheresis using the double filtration method was effective in improving the hearing ability of our patient. The mechanism of hearing loss in SLE has not been fully investigated. It has been suggested that the occurrence of thrombosis is related to the presence of anti-phospholipid antibodies (8). In the present study, the detection of anti-phospholipid antibodies in the 

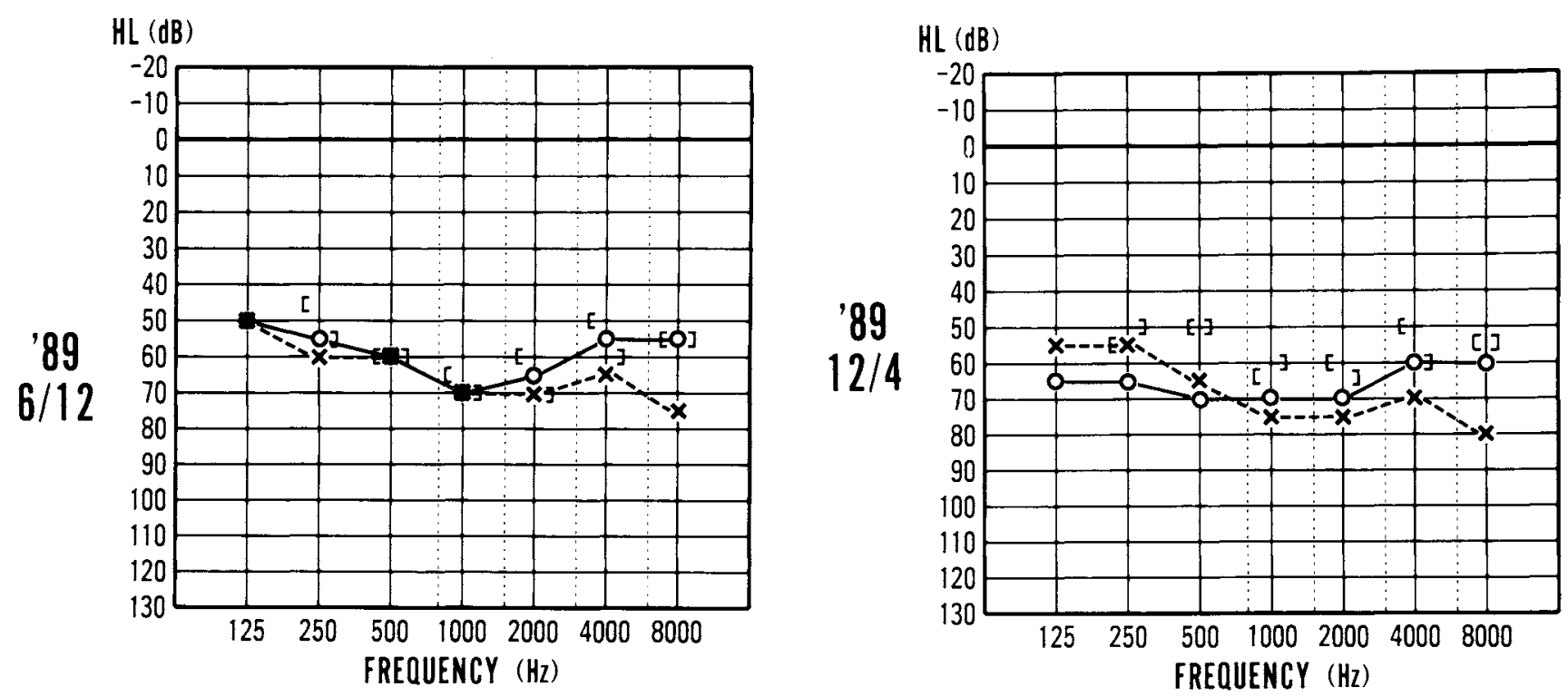

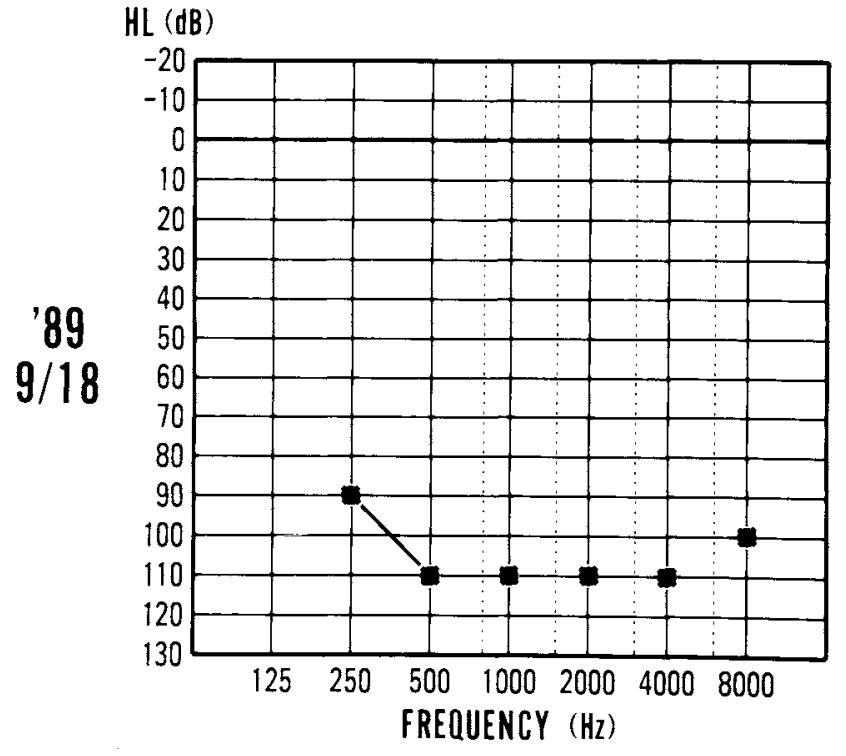

before plasmapheresis

Fig. 2. Audiogram before plasmapheresis treatment. The patient had severe hearing impairment.

serum was positively shown to relate to the patient's complications such as cerebral thrombosis and epilepsy. Carreras and Vermylen have suggested that the antiphospholipid antibodies might cause the endothelial cell damage which results in decreased prostacyclin production (9). Decreased prostacyclin levels would result in increased platelet aggregation and thrombosis. Although there is no direct evidence of the relationship between the presence of anti-phospholipid antibodies and the hearing loss in the present case, the improvement in the level of immune complex and anti-phospholipid antibodies after plasmapheresis treatment strongly

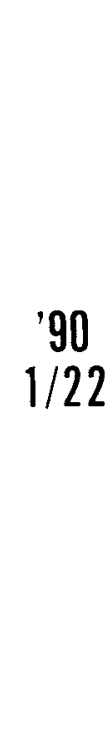

HL (dB)

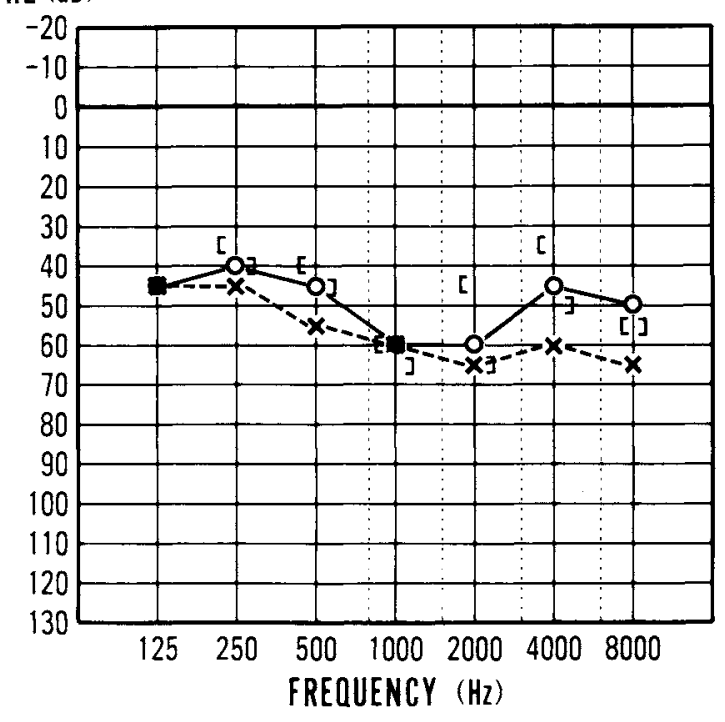

after plasmapheresis

Fig. 3. Audiogram after two series of plasmapheresis treatments. The patient's hearing ability was improved.

supports the theory that macromolecules, including anti-phospholipid antibodies, might play a pathological role in micro-circulation in the inner ear and impairment of hearing in SLE patients.

Treatment of hearing impairment in SLE patients is known to be a difficult problem. In addition to plasmapheresis treatment, which was proved to be effective in the present case, the use of anticoagulant and antiplatelet reagents should be considered if abovementioned disease mechanism is one of the causative factors. In order to elucidate the mechanism of hearing loss in SLE, future investigation should include the macro- 


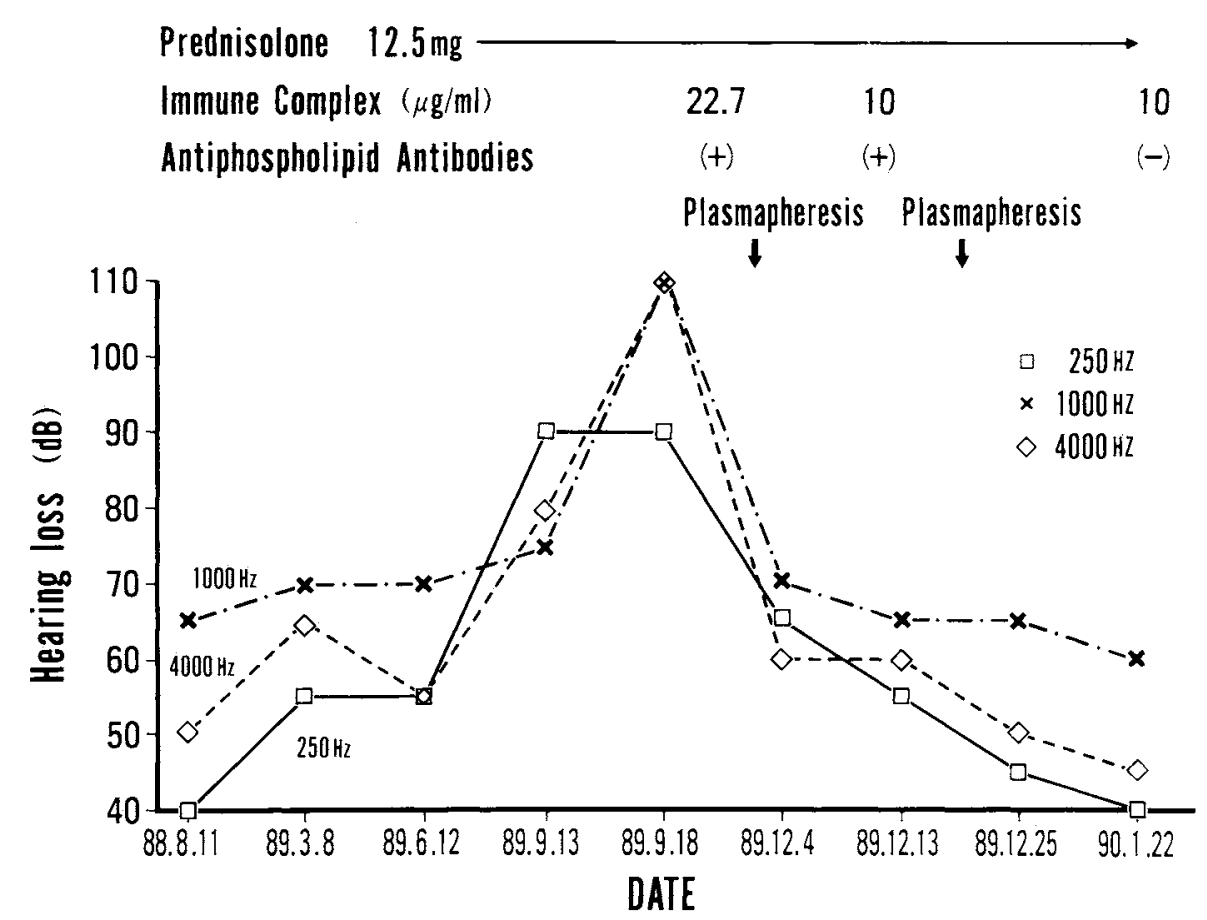

Fig. 4. This graph shows how the peak of the hearing loss in the patient's right car in September 1989, and the peak reduction after the two series of plasmapheresis treatments. The patient's immune complex level, anti-phospholipid antibodics and doses of prednisolone administerd are indicated.

molecules obtained in the fraction discarded during plasmapheresis.

\section{References}

1) Antes U, Heinz HP, Loos M. Detection of Clq-bearing immune complexes by a monoclonal anti-Clq ELISA system. J Immunol Methods 102: 149, 1987.

2) Agishi T, Kaneko I, Hasuo $Y$, et al. Double filtration plasmapheresis. Trans Am Soc Artif Intern Organs 26: 406, 1980.

3) Bowman CA, Linthicum FH, Nelson RA, Mikami K, Quismorio F. Sensorineural hearing loss associated with systemic lupus erythematosus. Otolaryngol Head Neck Surg 94: 197, 1986.

4) Caldarelli DD, Rejowski JE, Jacquelynne PC. Sensorineural hearing loss in lupus erythematosus. Am J Otolaryngol 7: 210, 1986.
5) McCabe BF. Autoimmune sensorineural hearing loss. Ann Otol 88: 585,1979

6) Lockwood CM, Worlledge S, Nicholas A, Cotton C, Peters DK. Reversal of impaired splenic function in patients with nephritis or vasculitis (or both) by plasma exchange. $\mathrm{N}$ Engl J Med 300: $524,1979$.

7) Hamblin TJ, Mufti GJ, Bracewell A. Severe deafness in systemic lupus erythematosus: its immediate relief by plasma exchange. $\mathrm{Br}$ Med J 284: 1374, 1982.

8) Harris EN, Gharavi AE, Boey ML, Patel BM, Mackworth-Youn $\mathrm{CG}$. Anticardiolipin antibodies: detection by radioimmunoassay and association with thrombosis in systemic lupus erythematosus. Lancet 2: 1211, 1983.

9) Carreras LO, Vermylen LG. 'Lupus' anticoagulant and thrombosis - possible role of inhibition of prostacyclin formation. Thromb Haemostasis 48: 28, 1982. 